\title{
Spina Bifida and Potatoes
}

\author{
C. A. CLARKE, OLIVE M. MCKENDRICK, P. M. SHEPPARD
}

British Medical fournal, 1973, 3, 251-254

Introduction

Summary

The results of a retrospective survey of the dietetic and other habits of the mothers of 83 children with spina bifida (mostly schoolchildren with meningomyelocele) were compared with 85 carefully matched controls. The survey was particularly concerned with the consumption of or contact with potatoes by the mothers. No significant differences were found in the amount of potatoes eaten as reported by the mothers (mean for spina bifida group $3.60 \mathrm{lb}(1630 \mathrm{~g})$, and for controls $3.98 \mathrm{lb}(1800 \mathrm{~g})$ per week). Of the seven other comparisons associated with potatoes only one (obtaining them from the chip shop or restaurant) was significant, the mothers of the children with spina bifida being more likely to obtain some of them from this source.

When examining other aspects of diet it was found that the mothers of spina bifida children reported a lower consumption of a number of important foods, though the deficiency was not significant in any instance. These mothers were also significantly more likely to have been prescribed drugs other than iron and vitamins early in pregnancy and to have reported a wider variety of illnesses.

The results in general do not support the hypothesis that the quantity of potatoes taken is important. They do lend support to the view that poor dietary habits are associated with $a$ higher incidence of spina bifida irrespective of social class. Furthermore, general ill health in the mother may be implicated.

Nuffield Unit of Medical Genetics, University of Liverpool C. A. CLARKE, F.R.C.P., F.R.S., Nuffield Research Fellow

Liverpool Corporation

OLIVE M. McKENDRICK, M.B., CH.B., School Medical Officer

Department of Genetics, University of Liverpool

P. M. SHEPPARD, D.PHIL., F.R.S., Professor of Genetics

Renwick (1972) put forward the hypothesis that most cases of anencephaly and spina bifida (S.B.) in the Western world are due to the mother eating or being in contact with potatoes infected with the fungus Phytophthora infestans during the early part of her pregnancy. The evidence for this suggestion was based on geographical and temporal correlations between the severity of potato blight and the incidence of these diseases. Renwick pointed out that the mechanism responsible was unknown, but he felt that the most likely explanation was that the teratogen was an antifungal product formed by the potato in response to the blight. The blight hypothesis was subsequently supported by the experimental findings of Poswillo et al. (1972) in marmosets.

Renwick thought that the only effective way of testing the hypothesis was to carry out a prospective survey of potato avoidance. We agree with this suggestion but large numbers of subjects would be required and it would be very difficult to supervise the experiment.

In the present study the converse approach, that of a retrospective survey, was attempted. The difficulties in such a study are well known and were aggravated in this instance by the fact that the events took place on average eight and a half years previously. Nevertheless, we felt that the opportunity presented by being able to investigate the mothers of 83 living children affected with spina bifida and a nearly equal number of matched controls should not be missed. We confined our attention to spina bifida for two reasons-(1) because the fact that the children were still living made it easier to contact the parents, and (2) because in any survey spina bifida and anencephaly must be treated separately, since there are large differences between them in respect of both mortality and sex ratio in the affected individuals.

The principal question which we have attempted to answer is the amount of potatoes eaten by the two groups of mothers at the time of the pregnancy in question. We appreciate that quantity may not be the sole or even the most important criterion, since a small number of blighted potatoes might be more damaging than a lot of unblighted ones. Nevertheless, quantity could be important, since, as Renwick pointed out, "If the proportion of rogue tubers is small the risk would be roughly proportional to the number of potatoes in the pan and therefore proportional to the aggregate appetite of the members of the household." 


\section{Subjects and Methods}

One of us (O. McK.) is a part-time school medical officer in charge of a special school for severe spina bifida cases. Some of these were available for study together with others taken from the records of the Education Department, where all children with meningomyelocele in Liverpool are assessed between the ages of 3 and 4 years for their future education. These two groups totalled 76 children born between 1960 and 1969. In addition seven recent cases were obtained from the neonatal unit of Alder Hey Hospital to study not only the diet of the mothers but also their antibody status in relation to $P$. infestans (these results are not yet available). To match the school cases 77 control children were picked by the school health visitors. They were instructed to choose for each affected child a control of the same sex, born in the same year and as nearly as possible in the same month as the propositus, now living in the same district of Liverpool, and as nearly as possible of the same social class, living in the same kind of accommodation. In the event they often lived very close to one another. The health visitors were in a good position to judge the social status of the families and did their best to match them, though not numerically. It was hoped that by taking these precautions we should eliminate any possible effect of sex, month and year of birth, and social class, previously postulated as being associated with the condition (see Renwick, 1972). This might help us to make meaningful comparisons between the two groups with respect to other factors not considered when matching the controls. In addition to the 77 school controls there were 8 matched for the recent cases. These were children either attending a school clinic or accompanying their mothers to an antenatal clinic near Sefton General Hospital.

When the propositi and controls had been obtained school health visitors were briefed to interview the mothers, and for this purpose we prepared a questionnaire. This included questions not only on potato ingestion but also on other aspects of diet. The school health visitors also inquired about family statistics, smoking, illnesses during the pregnancy, drugs, prophylactic inoculations, occupation, and household pets. This range of questions fulfilled two functions: firstly, to distract attention from the questions on potatoes and, secondly, to allow assessment of other possible factors in the aetiology of spina bifida. The school health visitors, not the mothers, filled in the questionnaires, and where we found the answers ambiguous we asked them to reinterview the mothers.

The information from the questionnaires was independently presented to two of us (C.A.C. and P.M.S.) in such a way that we did not know whether the propositus was a spina bifida case or a control. We recorded the data quantitatively where this was possible-for example, the number of pounds of potatoes eaten a week-and qualitatively, when the answer was almost always "yes" or "no"-for example, "Do you wear gloves when peeling potatoes ?" Our independent scores were then compared, and when agreement was reached a final score was recorded and then the code was broken.

\section{Results}

The qualitative answers were analysed using both $\chi^{2}$ and Fisher's two-tailed exact test and the quantitative data by the variance ratio and $t$ tests. Since the two groups of mothers might also be distinguishable by interactions between several factors rather than single ones a discriminative function analysis of the type used in taxonomy to distinguish populations was also used. The results of the single-factor comparisons are given in tables I to VI.

Among the qualitative comparisons 6 out of 40 reached the formal significance level of $P<0.05$. Among the quantitative ones, in 3 out of 15 the $t$ test reached this level of significance.

When the quantitative comparisons were examined a number of the variance ratio tests were also significant. This result probably stemmed from the fact that some of the distributions were not normal because the minimum value was zero, the mean was small, and the maximum could be quite large. To overcome this skewness these particular data were reanalysed after the addition of 1 to all the values and a log transformation. When this was done almost all of the variance ratios were very close to 1 and none was significant. Furthermore, of the two $t$ tests which had previously been significant (eggs and meat) neither remained so, though one (eggs, $t=1.93$ ) was still bordering on significance.

It might be argued that where the units are integers, such as the number of children in the family or the number of eggs eaten per week, a square root transformation would be more appropriate. When this was done the results were essentially the same as when using the log transformation.

The only other $t$ test which was significant-the comparison between year of birth of spina bifida children and their sibs-did not require a transformation.

Looking at the results as a whole there are 7 out of 55 comparisons which are significant. When considering these it must be remembered that in making so many comparisons a number of significant deviations are likely to occur by chance alone. In order to try to overcome this difficulty we analysed the two groups by a discriminant function analysis of the sort used in systematics to distinguish taxa. We excluded those factors which were used in the choice of controls, together with the presence of congenital abnormalities in the family (likely to be biased) and whether the mothers had moved subsequent to the pregnancy, which must be irrelevant. When this was done the analysis showed no overall significant difference between the two groups $\left(x_{50}^{2} 66 \cdot 83,0 \cdot 1>\right.$ P 70.05).

\section{Discussion}

\section{CONTROLS}

In any retrospective survey dealing with spina bifida the selection of controls is of particular importance because of the evidence that the incidence of the condition varies with social class (Laurence et al., 1968), sex (Carter et al., 1968), and locality as well as month and year of birth (Renwick, 1972).

In order to test how well our controls matched the index cases with respect to these features we examined them for significant differences (table I). In none of the comparisons is there any evidence of a difference between the propositi and the controls. Since we did not assess social class numerically we selected comparable neighbours as controls, so that the comparison in table I listed "locality" is likely to be an assessment of social class and is not concerned with regional differences. Despite the fact that we picked the controls according to their present address it is seen that when the locality at the time of the particular pregnancy is compared there is no suggestion of any difference between the two groups.

\section{ROLE OF POTATOES}

The investigation was primarily to study the role of potatoes in spina bifida, and in table II are listed the comparisons which Renwick's paper suggested to us might be of importance (including the size of the household and help in the preparation of food, which might affect the number of potatoes handled).

Since the events being investigated took place up to 12 years previously the absence of associations may be due to the difficulties of recalling habits accurately. Nevertheless, it is interesting to note that there is no evidence for a correlation between the estimated consumption of potatoes by the mother during the pregnancy in question and the probability of spina bifida in the child. One of the mothers of an affected child, in 
TABLE I-Degree of Matching between Propositi and Control Children with Respect to Characters for which Controls were chosen

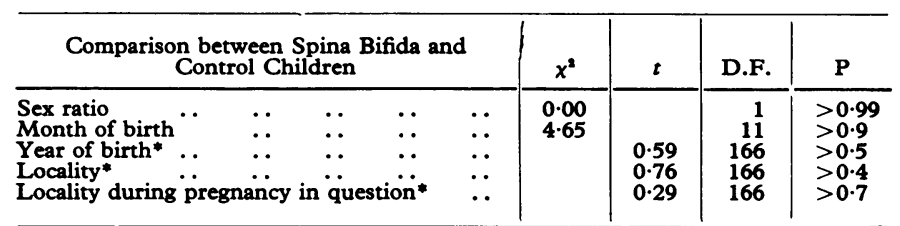

* Locality was the Liverpool district number of the present address of the family 0 was used in the few cases where the family did not live on Merseyside. Though year of birth and district number are not normally distributed we have used a $t$ test for the comparisons because there were too many categories with too few individuals in each category to use a $x^{2}$ test effectively.

D.F. $=$ Degrees of freedom.

TABLE II-Contact with Potatoes of Mothers with Affected and Unaffected Children

\begin{tabular}{|c|c|c|c|c|c|c|}
\hline Comparison & & $x^{2}$ & & $t^{*}$ & D.F. & $\mathbf{P}$ \\
\hline $\begin{array}{l}\text { Consumption per week } \\
\text { Peeling of potatoes } \\
\text { Wearing of gloves when peelin } \\
\text { Size of household } \\
\text { Help in preparation of food } \\
\text { Source of potatoes: } \\
\text { Greengrocer . . . } \\
\text { Chip shop or restaurant } \\
\text { "Elsewhere" . . .. }\end{array}$ & $\begin{array}{l}\ddot{y} \\
\ddot{\mathrm{ng}} \\
\ddot{ } \\
\cdots \\
\cdots\end{array}$ & 0.28 & $\begin{array}{l}\text { Exact test } \nmid \\
\text { Exact test }\end{array}$ & $\begin{array}{l}-1 \cdot 00 \\
- \\
+ \\
+0.90 \\
+ \\
+ \\
+ \\
+\end{array}$ & $\begin{array}{r}166 \\
166 \\
1\end{array}$ & $\begin{array}{l}>0.3 \\
0.097 \\
0.745 \\
>0.3 \\
>0.5 \\
0.443 \\
0.045 \\
0.497\end{array}$ \\
\hline
\end{tabular}

* In tables II to $\mathrm{V} \mathrm{a}+$ in the $t$ column means that the mothers of spina bifida children took or "experienced" more than the controls of the factor being tested.
$t$ "Exact test" was Fisher's exact test for a $2 \times 2$ contingency table.

fact, stated that she had not eaten potatoes, and this was true of two of the controls.

The only significant comparison associated with potatoes was their origin, 20 mothers of spina bifida children obtaining some of their potatoes ready fried from the chip shop compared with only 10 of the controls. Because of the small numbers involved the probability was calculated using Fisher's exact test $(P=0.045)$. Since the 16 chip shops questioned bought the cheapest old potatoes available, people who consistently obtained their potatoes from this source would tend to eat less good quality ones as compared with those who bought them from the greengrocer. In our survey nobody obtained them exclusively from the chip shop.

The geographical origin of potatoes varies somewhat in Liverpool in different seasons but the pattern remains fairly constant from year to year. According to the greengrocers interviewed the cheaper potatoes are grown locally. The more expensive English ones come from Lincolnshire, and those from Cyprus (even more expensive) are imported early in the year before the local varieties are ready. The cheapest potatoes are more likely to be blighted, but this should not affect our results because of the way the controls were matched. If there are differences between the origin of potatoes at different times of the year, and if this is important in the aetiology of spina bifida, one might expect a significant effect of month of birth in a comparison between affected children and their sibs. The controls cannot be used since they were matched for month. Examination of table $\mathrm{V}$ shows no evidence of such an effect.

\section{OTHER ASPECTS OF DIET}

In the initial analysis (table III) the reported consumption of eggs and meat was significantly lower in the mothers of spina bifida children than in the controls. Moreover, there was a non-significant reduction in fish, cheese, fruit, salad, and tea. Only with respect to coffee was there a nonsignificant excess among the mothers of affected children. On reanalysis using a log transformation (see above) the two significant comparisons ceased to be so, but none of the deficiencies was turned into an excess. Overall this suggests that the mothers of spina bifida children may have a poorer diet than the controls, even though they come from the same social group.

TABLE III-Other Aspects of Diet

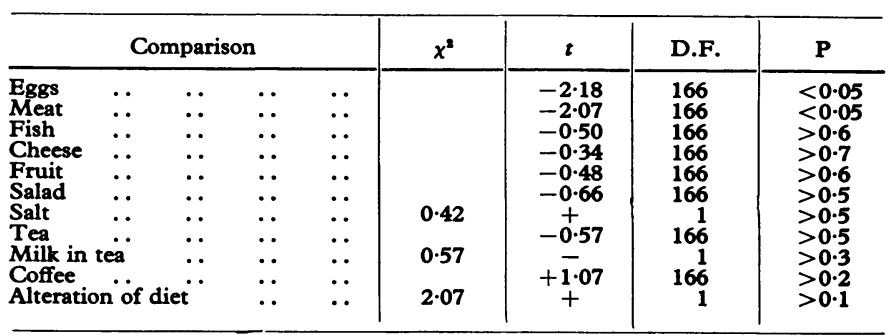

\section{DRUGS, MEDICAMENTS, AND ILLNESSES}

Among the comparisons in table IV there are three significant differences, and the first two concern drugs other than iron and vitamins. The data for these other drugs were examined in two ways, in relation to the proportion of mothers who took them $(a)$ at some time during the pregnancy and $(b)$ in the first three months.

The third comparison was the incidence of illnesses other than toxaemia, pyelitis, and anaemia (the three conditions numerous enough to analyse individually). Of these, toxaemia is a condition of late pregnancy and would therefore not be expected to cause spina bifida. Of the other two, which more frequently occur early in pregnancy, neither showed a correlation with spina bifida, though there were more cases of pyelitis (six as against two) in the mothers of spina bifida children compared with the controls.

Among the other diseases none was represented more than once, though there were seven in the mothers of affected children and only one in the controls. If the results are not due to chance they may just indicate "poor health" rather than a specific causative agent.

There was no detectable effect of cigarette smoking, and among prescribed drugs neither the necessity for iron nor that for vitamins showed a detectable correlation with spina bifida. All the other drugs prescribed were so infrequent as to be unanalysable separately but when taken together did show a significant difference. The biggest contribution to this was in the frequency with which prescribed antidepressants and sedatives were taken in the first three months, there being five in the mothers of spina bifida children and none in the controls. Like the illnesses this might indicate debility, but the drugs cannot in themselves be the sole or even an important cause of spina bifida.

TABLE IV-Illnesses, Medicaments, and Other Drugs

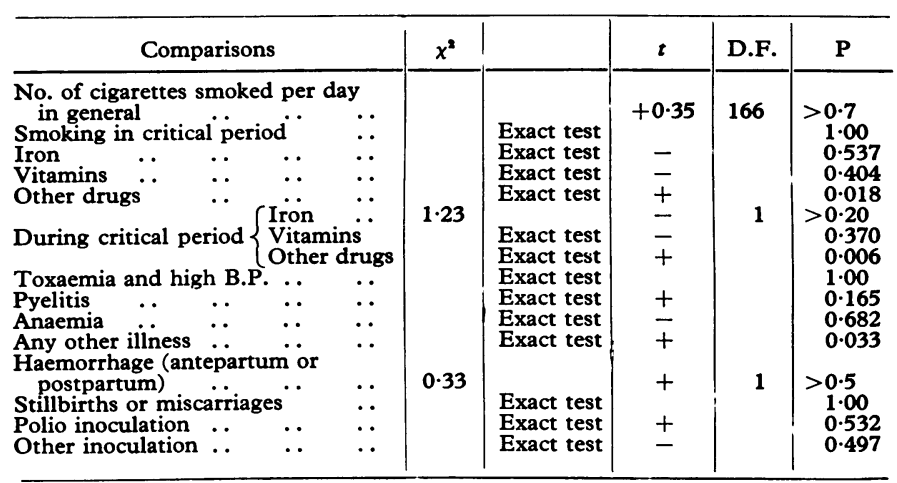


TABLE V-Family Statistics

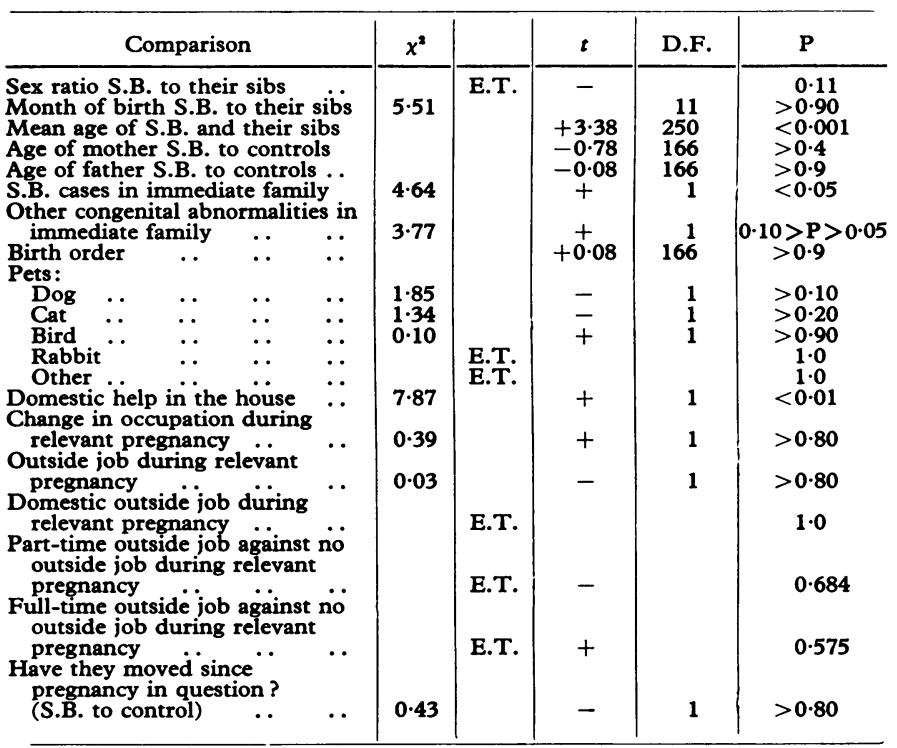

E.T. $=$ Exact test

TABLE VI-Means and Standard Deviations for Comparisons analysed by $\mathrm{t}$ Test (using Untransformed Data)

\begin{tabular}{|c|c|c|c|c|c|c|}
\hline \multirow{2}{*}{\multicolumn{3}{|c|}{ Comparison }} & \multicolumn{2}{|c|}{ Affected } & \multicolumn{2}{|c|}{ Control } \\
\hline & & & \multirow[b]{2}{*}{$\begin{array}{c}\text { Mean } \\
3.60 \\
3.81 \\
3.77 \\
1.40 \\
0.36 \\
0.40 \\
1.95 \\
1.49 \\
5.57 \\
1.34 \\
6.67 \\
26.78 \\
30.08 \\
2.28 \\
64.35\end{array}$} & \multirow[b]{2}{*}{$\begin{array}{l}\text { S.D. } \\
1.82 \\
1.80 \\
3.00 \\
0.60 \\
0.35 \\
0.38 \\
1.04 \\
1.17 \\
3.85 \\
2.03 \\
7.48 \\
5.96 \\
7.29 \\
1.49 \\
3.09\end{array}$} & \multirow[b]{2}{*}{$\begin{array}{r}\text { Mean } \\
3.98 \\
3.58 \\
5.15 \\
1.64 \\
0.39 \\
0.42 \\
2.02 \\
1.61 \\
5.92 \\
1.00 \\
6.24 \\
27.53 \\
30 \cdot 18 \\
2.26 \\
62.26\end{array}$} & \multirow[b]{2}{*}{$\begin{array}{l}\text { S.D. } \\
2.90 \\
1.52 \\
4.96 \\
0.86 \\
0.42 \\
0.38 \\
1.06 \\
1.14 \\
4.07 \\
2.09 \\
8.06 \\
6.45 \\
7.44 \\
1.42 \\
5.20\end{array}$} \\
\hline $\begin{array}{l}\text { Consumption (lb per week }{ }^{*} \text { ) of } \\
\text { Size of household } \\
\text { No. of eggs eaten per week } \\
\text { Meat (1b eaten per week) } \\
\text { Fish (lb eaten per week) } \\
\text { Cheese (lb eaten per week) } \\
\text { Fruitt } . \\
\text { Saladt } \ldots \\
\text { No. of cups of tea per day } \\
\text { No. of cups of coffee per day } \\
\text { No. of cigarettes per day } \\
\text { Age of mothers of S.B. to contr } \\
\text { Age of fathers of S.B. to contro } \\
\text { Position in sibship S.B. to cont } \\
\text { Year of birth of S.B. children a }\end{array}$ & 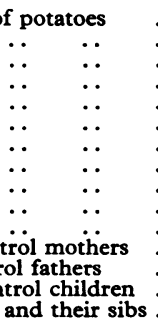 & $\begin{array}{l}\because \\
\because \\
\because \\
\because \\
\because \\
\because \\
\because \\
\because \\
\because \\
\therefore\end{array}$ & & & & \\
\hline
\end{tabular}

$1 \mathrm{lb}=450 \mathrm{~g}$.

We divided the quantities taken into four categories-none, very little, average, and not judge the weight.

\section{FAMILY STATISTICS}

As in the other tables most of the comparisons were nonsignificant (table V), and it is particularly interesting to note that with regard to month of birth there is no significant difference between the affected children and their unaffected sibs, though the numbers involved would detect only rather large differences. With regard to the mean age of affected children and their sibs the average age of the sibs was 2 years older than the spina bifida cases, probably indicating that parents tend to stop having children after giving birth to a child with the disease. The controls tend to support this view, since they had more children after the index case. The difference is not due to the probability of spina bifida children increasing with parity, since the comparison of birth order with controls shows no significant difference.
Congenital abnormalities, whether spina bifida or not, were reported more frequently among the families of relatives in the affected group. This may well be due to bias, since the mothers of spina bifida children would be more aware of congenital malformation among their relatives.

There was a significant excess of mothers of spina bifida children who had help with their domestic work other than cooking. We can suggest no explanation for this other than chance, unless it was again an indication of "poor health."

\section{Conclusions}

Within its limitations this investigation lends no support to the hypothesis that the quantity of potatoes eaten or handled plays any part in the causation of spina bifida. It is of particular interest that figures for consumption were slightly less in the mothers of affected children, whereas one might have expected bias in the opposite direction, since most of the mothers knew about the potato hypothesis at the time of the inquiry (though not, of course, during their pregnancy).

As regards quality it is true that chip shops usually use inferior potatoes, but we feel that the chip shop effect, if real, is much more likely to be an indicator of poor dietary habits, perhaps associated with indifferent health.

Though there were indications of differences between the two groups of mothers the discriminant function showed no overall difference between them. This may be because there is no difference with respect to the factors we have analysed, or because many of them are irrelevant, swamping the effects of the relevant ones. Because of this we propose to investigate a similar group of mothers of affected children, this time younger children, confining our attention to those factors that were suggestive in the present survey, together with a limited number of others such as preserved meats (because of their nitrite content), as proposed by Knox (1972) for anencephaly.

Many authors have presented evidence that spina bifida is much commoner among social classes IV and V (see Laurence et al., 1968). The environmental agents responsible for this class difference in the incidence are entirely unknown, but it has been suggested that one may be poor nutrition. Our data, which attempted to remove the effects of social class, support the nutritional view and in addition suggest that general ill health in the mother may also be a factor.

We wish to thank Professor A. B. Semple, medical officer of health and principal school medical officer, Dr. A. M. Brown, of the School Health Department, City of Liverpool, Miss M. J. Dyke, superintendent of school nurses, and the school health visitors for their enthusiastic help and co-operation in this study. We are greatly indebted to Mr. R. J. White for using his computer program for the discriminant function analysis. We are particularly grateful to the Nuffield Foundation for its continued support.

\section{References}

Carter, C. O., David, P. A., and Laurence, K. M. (1968). fournal of Medical Genetics, $\mathbf{5}, 81$

Knox, E. G. (1972). British fournal of Preventive and Social Medicine, 26, 219 .

Laurence, K. M., Carter, C. O., and David, P. A. (1968). British fournal of Preventive and Social Medicine, 22, 212.

Poswillo, D. E., Hamilton, W. J., and Sopher, D. (1972). Nature, 239, 460. 26, 67. H. (1972). British fournal of Preventive and Social Medicine,
Rick, 